\title{
Faktor-Faktor Yang Berhubungan Dengan Safe Staffing Di Rumah Sakit
}

\section{Deni Erhardi ${ }^{1 *}$, Sri Yulia ${ }^{2}$, Muliyadi ${ }^{3}$}

${ }^{1}$ Program Studi Ilmu Keperawatan Sekolah Tinggi Ilmu Kesehatan Muhammadiyah Palembang, Palembang, 30262, Sumatera Selatan, Indonesia.

${ }^{2}$ Deparetmen Keperawatan, Program Studi Ilmu Keperawatan Sekolah Tinggi Ilmu Kesehatan Muhammadiyah Palembang, Palembang, 30262, Sumatera Selatan, Indonesia.

${ }^{3}$ Deparetmen Keperawatan, Program Studi Ilmu Keperawatan Politeknik Kesehatan Kementerian Kesehatan Palembang, Palembang, 30151, Sumatera Selatan, Indonesia.

*korespondensi: erhardi.deni@gmail.com

\begin{abstract}
Abstrak: Ketersediaan sumber daya keperawatan, lingkungan kerja perawat yang kondusif dan membangun sistem pelayanan kesehatan yang aman merupakan faktor yang berhubungan dengan safe staffing. Tujuan penelitian ini untuk mengidentifikasi faktor-faktor yang berhubungan dengan safe staffing di Rumah Sakit. Jenis penelitian bersifat kuantitatif menggunakan survey cross sectional. Teknik pengambilan sampel yaitu total sampling sebanyak 48 responden perawat. Ada hubungan yang signifikan antara ketersediaan sumber daya keperawatan dengan safe staffing ( $\mathrm{p}$ value $=0,001$ ), ada hubungan yang signifikan antara lingkungan kerja perawat yang kondusif dengan safe staffing ( $\mathrm{p}$ value $=0,027$ ), dan ada hubungan yang signifikan antara membangun sistem pelayanan kesehatan yang aman dengan safe staffing dengan ( $\mathrm{p}$ value $=0,000$ ). Bidang keperawatan bersama-sama dengan Komite Keselamatan Rumah Sakit dapat mengembangkan perencanaan peningkatan kualitas SDM melalui pelatihan dan pendidikan sesuai kompetensi perawat, memberikan reward kepada perawat, peningkatan status kepegawaian.
\end{abstract}

Kata kunci: Safe Staffing, Lingkungan Kerja Perawat, Tempat Kerja Perawat, Lokasi Kerja Perawat.

Abstract: The availability of nursing resources, conducive work atmosphere for nurses and creating safe health service are the factors related to safe staffing. If one of these three aspects is not fulfilled, it can cause low health service quality given by the hospital. The purpose to identify the factors related to safe staffing at Hospital. This study is a quantitative study using cross sectional survey. The samples were taken by applying total sampling method, there were 48 nurses taken as the respondents. There was a significant correlation between the availability of nursing resources and safe staffing ( $p$ value $=0,001$ ), there was a significant correlation between conducive work atmosphere and safe staffing ( $p$ value $=0,027$ ), and there was a significant correlation between creating safe health service system and safe staffing ( $p$ value $=0,000$ ). Very important that Hospital apply safe staffing. Nursing department together with Hospital Safety Committee can develop the plan to increase human resources quality by giving training in accordance with nurses' competence, giving reward to nurses, and improving the employees' status.

Keyword: Safe Staffing, Nurse Work Environment, Nurse Workplace, Nurse Work Location. 


\section{PENDAHULUAN}

Sumber daya manusia di rumah sakit menjadi hal penting yang mendukung berkembangnya rumah sakit dan menjadi tolak ukur penting dalam penilaian pengembangan mutu pelayanan di rumah sakit. Keberadaan perawat sebagai bagian dari sumber daya manusia di bidang kesehatan yang ada di rumah sakit sebagai profesi yang memiliki waktu interaksi lebih lama dibandingkan dengan profesi lain dalam suatu rumah sakit memiliki peran kritis yang sangat penting dalam memberikan pelayanan kesehatan yang berfokus pada keselamatan pasien. Dengan demikian bahwa mutu pelayanan yang baik memerlukan sumber daya manusia yang berkualitas sehingga terpenuhinya keselamatan staf dan pasien (Fera, 2015)

Safe staffing berarti bahwa jumlah staf yang berkerjasama sesuai dengan tingkat keahliannya, tersedia setiap saat untuk memastikan bahwa kebutuhan perawatan pasien terpenuhi dan kondisi kerja staf yang terbebas dari bahaya (hazardfree) dapat dipertahankan. Pengelolaan safe staffing mencerminkan dari kualitas perawatan pasien, kehidupan kerja yang aman seorang perawat. Praktik Safe staffing menggabungkan seluruh kegiatan keperawatan dan berbagai tingkat kemampuan persiapan perawat, kompetensi, pengalaman, pengembangan kesehatan pribadi perawat. Dukungan dari manajemen keperawatan di tingkat operasional serta eksekutif seperti lingkungan kontekstual, dukungan layanan teknologi dari fasilitas yang tersedia; serta penyediaan perlindungan dari pihak yang berwenang (whistleblower) (ICN, 2006). Hal ini berarti bahwa safe staffing adalah bagaimana menciptakan kondisi kerja bagi perawat yang aman yang di indikasikan dengan kecukupan jumlah staf perawat yang sesuai dengan kompetensi, dan mampu bekerja sama dalam satu teamwork sehingga dapat memberikan keperawatan pasien yang aman.

Faktor-faktor yang mempengaruhi safe staffing diantaranya adalah ketersediaan sumber daya yang optimal yang dimiliki oleh organisasi pelayanan kesehatan yang meliputi kesesuaian antara jumlah perawat dengan jumlah pasien yang dilayani, skill mix dan peningkatan kompetensi dalam pelayanan keperawatan. Safe staffing juga dipengaruhi oleh lingkunan kerja yang kondusif seperti budaya kerja dan pola komunikasi diantara staf yang harmonis, serta sistem perlindungan hukum bagi tenaga keperawatan (ICN, 2006).

Kebijakan mengenai Safe staffing and Saves Lives (ICN, 2006) dan Islamabad Declaration on Strengthening Nursing and Midwifery (WHO \& ICN, 2007) telah disepakati secara global untuk mendukung keselamatan pasien dan sumber daya manusia keperawatan. Peningkatan lingkungan kerja bagi perawat merupakan salah satu aspek yang harus dikembangkan dalam pencapaian Safe staffing and Saves Lives.

Berdasarkan uraian diatas penelitian ini bertujuan untuk mengetahui Faktor-Faktor yang Berhubungan dengan Safe staffing di Rumah Sakit X Palembang Tahun 2017"

\section{METODE}

Penelitian ini bersifat kuantitatif menggunakan metode penelitian survey cross sectional. Populasi penelitian ini adalah semua perawat di ruangan yaitu Pavilium Suprapto, Cendana, Jana Nuraga 1 dan Jana Nuraga II Rumah Sakit X Palembang Tahun 2017 yang berjumlah 48 responden.Teknik sampling yang digunakan dalam penelitian ini yaitu total sampling yaitu metode seluruh populasi diambil untuk dijadikan sampel. Dalam penelitian ini jumlah sampel adalah seluruh perawat ruangan di RS X sebanyak 48 orang yang sesuai dengan kriteria inklusi.

Penelitian ini dilaksanakan diseluruh Ruang Rawat Inap Rumah Sakit X Palembang Tahun 2017. Alat pengumpulan data menggunakan kuesioner sebanyak 32 item pernyataan yang terdiri dari safe staffing 8 item, ketersediaan sumber daya keperawatan sebanyak 8 item, lingkungan kerja perawat yang kondusif sebanyak 8 item, dan membangun sistem pelayanan kesehatan yang aman sebanyak 8 item. Penelitian ini menggunakan uji Chi Square dengan derajat kepercayaan $95 \%(\alpha 0,05)$. 
HASIL

\section{Analisa Univariat}

Tabel 1. Distribusi Rata-Rata Menurut Usia Responden di RS X Palembang

\begin{tabular}{cccccc}
\hline Variabel & Mean & SD & Min & Max & 95\% CI \\
\hline Usia & 27,19 & 2,788 & 22 & 33 & $26,38-28,00$ \\
\hline
\end{tabular}

Berdasarkan tabel 5.1 didapatkan rata-rata usia responden pada penelitian ini yaitu 27,19 tahun dengan besarnya simpangan baku 2,788 hal ini menunjukkan sebaran data atau variansinya bernilai kecil sehingga data semakin homogen. Untuk estimasi interval 95\% kita yakin bahwa rata-rata usia responden berada pada selang $26,38 \mathrm{~s} / \mathrm{d} 28,00$.

Tabel 2. Distribusi Frekuensi Responden Berdasarkan Jenis Kelamin Responden di RS X Palembang

\begin{tabular}{ccc}
\hline Jenis Kelamin & F & \% \\
\hline Laki-Laki & 14 & 29,2 \\
Perempuan & 34 & 70,8 \\
Total & 48 & 100 \\
\hline
\end{tabular}

Berdasarkan tabel 5.2 diatas bahwa jenis kelamin responden yang terbesar dalam penelitian ini yaitu perempuan sebanyak 34 responden (70,8\%) sedangkan yang berjenis kelamin laki-laki sebanyak 14 orang $(29,2 \%)$. Dengan demikian maka sebagian besar responden dalam penelitian ini berjenis kelamin perempuan.

Tabel 3. Distribusi Frekuensi Responden Berdasarkan Pendidikan Responden Di RS X Palembang

\begin{tabular}{ccc}
\hline Pendidikan & F & \% \\
\hline D. III Keperawatan & 38 & 79,2 \\
S1 Keperawatan & 1 & 1 \\
S1 Keperawatan + Ners & 9 & 18,8 \\
Total & 48 & 100 \\
\hline
\end{tabular}

Berdasarkan tabel 5.3 diatas bahwa tingkat pendidikan responden yang terbanyak dalam penelitian ini yaitu D.III Keperawatan sebanyak 38 responden $(79,2 \%)$ dan terendah dengan tingkat pendidikan sebanyak 1 responden (1\%). Maka sebagian besar responden berpendidikan D.III Keperawatan.

Tabel 4. Distribusi Rata-Rata Menurut Lama Bekerja Responden di RS X Palembang

\begin{tabular}{cccccc}
\hline Variabel & Mean & SD & Min & Max & 95\% CI \\
\hline Lama Bekerja & 4,25 & 2,188 & 1 & 8 & $3,61-4,89$ \\
\hline
\end{tabular}

Berdasarkan tabel 5.4 didapatkan rata-rata lama bekerja responden pada penelitian ini yaitu 4,25 tahun dengan simpangan baku sebesar 2,188 hal ini menunjukkan sebaran data atau variansinya bernilai kecil sehingga data semakin homogen. Masa kerja terendah yaitu 1 tahun dan yang tertinggi yaitu 8 tahun. Untuk estimasi interval 95\% kita yakin bahwa rata-rata lama bekerja responden berada pada selang 3,61 s/d 4,89. 
Tabel 5. Distribusi Frekuensi Responden Berdasarkan Status Responden di RS X Palembang

\begin{tabular}{ccc}
\hline Status & F & \% \\
\hline Tetap & - & - \\
Tidak Tetap & 48 & 100 \\
Total & 48 & 100 \\
\hline
\end{tabular}

Berdasarkan tabel 5 diatas bahwa status responden semuanya adalah tidak tetap yaitu sebanyak $100 \%$. Sebagian besar responden masih berstatus kepegawaian tidak tetap atau sebagai tenaga BLU.

Tabel 6. Distribusi Frekuensi Persepsi Responden Terhadap Ketersediaan Sumber Daya Keperawatan di RS X Palembang

\begin{tabular}{ccc}
\hline Ketersediaan Sumber Daya Keperawatan & F & \% \\
\hline Baik & 24 & 50 \\
Tidak Baik & 24 & 50 \\
Total & 48 & 100 \\
\hline
\end{tabular}

Berdasarkan tabel 5.6 diatas bahwa sebanyak 24 responden atau 50\% mempersepsikan bahwa sumber daya keperawatan sudah baik dan sebanyak 24 responden atau 50\% mempersepsikan bahwa sumber daya keperawatan tidak baik. Proporsi perawat yang mempersepsikan bahwa sumber daya keperawatan sudah baik dengan tidak baik proposinya sama.

Tabel 7. Distribusi Frekuensi Persepsi Responden Terhadap Lingkungan Kerja Kondusif di RS X Palembang

\begin{tabular}{ccc}
\hline Lingkungan Kerja Kondusif & F & \% \\
\hline Baik & 30 & 62,5 \\
Tidak Baik & 18 & 37,5 \\
Total & 48 & 100 \\
\hline
\end{tabular}

Berdasarkan tabel 5.7 diatas bahwa responden yang mempersepsikan bahwa lingkungan kerja yang kondusif sudah baik sebanyak 30 responden atau 62,5\% dan mempersepsikan bahwa lingkungan kerja yang kondusif tidak baik sebanyak 18 responden atau 37,5\%. Proporsi perawat yang mempersepsikan lingkungan kerja yang kondusif sebagian besar sudah baik tetapi belum dominan.

Tabel 8. Distribusi Frekuensi Persepsi Responden tentang Membangun Sistem Pelayanan Kesehatan yang Aman di RS X Palembang

\begin{tabular}{ccc}
\hline Membangun Sistem Pelayanan Kesehatan yang Aman & F & \% \\
\hline Baik & 35 & 72,9 \\
Tidak Baik & 13 & 27,1 \\
Total & 48 & 100 \\
\hline
\end{tabular}

Berdasarkan tabel 5.7 diatas bahwa responden yang mempersepsikan bahwa membangun sistem pelayanan kesehatan yang aman sudah baik sebanyak 35 responden atau $72,9 \%$ dan mempersepsikan bahwa membangun sistem pelayanan kesehatan yang aman tidak baik sebanyak 13 responden atau $27,1 \%$. Hal ini berarti bahwa sebagian besar perawat mempersepsikan membangun sistem pelayanan kesehatan yang aman sudah baik. 
Tabel 9. Distribusi Frekuensi Persepsi Responden tentang Safe Staffing di RS X Palembang

\begin{tabular}{ccc}
\hline Safe staffing & F & \% \\
\hline Baik & 32 & 66,7 \\
Tidak Baik & 16 & 33,3 \\
Total & 48 & 100 \\
\hline
\end{tabular}

Berdasarkan tabel 9 diatas bahwa responden yang mempersepsikan bahwa Safe staffing sudah baik sebanyak 32 responden atau $66,7 \%$ dan mempersepsikan bahwa Safe staffing tidak baik sebanyak 16 responden atau 33,3\%. Persepsi perawat mengenai safe staffing sebagian besar sudah baik.

\section{Analisa Bivariat}

Tabel 10. Distribusi Hubungan Ketersediaan Sumber Daya Keperawatan Dengan Safe Staffing di Rumah Sakit X Palembang Tahun 2017

\begin{tabular}{ccccccccc}
\hline \multirow{2}{*}{$\begin{array}{c}\text { Ketersediaan } \\
\text { Sumber Daya }\end{array}$} & \multicolumn{9}{c}{ Baik } & \multicolumn{3}{c}{ Safe staffing } & \multirow{2}{*}{ OR } & \multirow{2}{*}{$\begin{array}{c}\text { Nilai } P \\
\text { value }\end{array}$} \\
\cline { 2 - 7 } Keperawatan & $\mathrm{n}$ & $\%$ & $\mathrm{n}$ & $\%$ & $\mathrm{n}$ & $\%$ & & \\
\cline { 2 - 8 } Baik & 22 & 91,7 & 2 & 8,3 & 24 & 100 & & \\
Tidak Baik & 10 & 41,7 & 14 & 58,3 & 24 & 100 & & 0,001 \\
Total & 32 & 66,7 & 16 & 33,3 & 48 & 100 & \\
\hline
\end{tabular}

Berdasarkan analisis hubungan antara ketersediaan sumber daya keperawatan dengan safe staffing diketahui bahwa dari 24 responden yang mempersepsikan ketersediaan sumber daya keperawatan yang baik sebanyak 22 responden atau 91,7\% mempersepsikan safe staffing sudah baik dan dari 24 responden yang mempersepsikan ketersediaan sumber daya keperawatan yang tidak baik sebanyak 10 responden atau $41,7 \%$ mempersepsikan safe staffing sudah baik.

Hasil uji chi square didapatkan nilai $\mathrm{p}($ Value $)=0,001$ lebih kecil dari $\alpha=0,05$ sehingga dapat disimpulkan ada hubungan yang signifikan antara ketersediaan sumber daya keperawatan dengan Safe staffing dan dari hasil analisis diperoleh nilai $\mathrm{OR}=15,4$ artinya ketersediaan sumber daya keperawatan yang baik mempunyai peluang 15,4 kali untuk menciptakan safe staffing dibandingkan dengan ketersediaan sumber daya keperawatan yang tidak baik.

Tabel 11. Distribusi Hubungan Lingkungan Kerja Perawat yang Kondusif dengan Safe Staffing di Rumah Sakit X Palembang Tahun 2017

\begin{tabular}{|c|c|c|c|c|c|c|c|c|}
\hline \multirow{3}{*}{$\begin{array}{l}\text { Lingkungan kerja } \\
\text { Perawat yang } \\
\text { Kondusif }\end{array}$} & \multicolumn{6}{|c|}{ Safe staffing } & \multirow{3}{*}{ OR } & \multirow{2}{*}{$\begin{array}{c}\text { Nilai } P \\
\text { value }\end{array}$} \\
\hline & \multicolumn{2}{|c|}{ Baik } & \multicolumn{2}{|c|}{ Tidak Baik } & \multicolumn{2}{|c|}{ Total } & & \\
\hline & $\mathrm{n}$ & $\%$ & $\mathrm{n}$ & $\%$ & $\mathrm{~N}$ & $\%$ & & \multirow{4}{*}{0,027} \\
\hline Baik & 24 & 80,0 & 6 & 20,0 & 30 & 100 & \multirow{3}{*}{5,0} & \\
\hline Tidak Baik & 8 & 31,3 & 10 & 55,6 & 18 & 100 & & \\
\hline Total & 32 & 66,7 & 16 & 33,3 & 48 & 100 & & \\
\hline
\end{tabular}

Berdasarkan analisis hubungan antara lingkungan kerja perawat yang kondusif dengan Safe staffing diketahui bahwa dari 30 responden yang mempersepsikan lingkungan kera perawat yang kondusif sudah baik sebanyak 24 responden atau $80 \%$ mempersepsikan safe staffing sudah baik dan 
dari 18 responden yang mempersepsikan lingkungan kerja yang kondusif yang tidak baik, ada sebanyak 8 responden atau 31,3\% mempersepsikan safe staffing sudah baik.

Hasil uji chi square didapatkan nilai $\mathrm{p}($ Value $)=0,027$ lebih kecil dari $\alpha=0,05$ sehingga dapat disimpulkan ada hubungan yang signifikan antara lingkungan kerja perawat yang kondusif dengan Safe staffing dan dari hasil analisis diperoleh nilai OR $=5,0$ artinya lingkungan kerja perawat yang baik mempunyai peluang 5,0 kali untuk menciptakan safe staffing dibandingkan dengan lingkungan kerja perawat yang tidak baik.

Tabel 12. Distribusi Hubungan Membangun Sistem Pelayanan Kesehatan yang Aman dengan Safe staffing di Rumah Sakit X Palembang Tahun 2017

\begin{tabular}{|c|c|c|c|c|c|c|c|c|}
\hline \multirow{3}{*}{$\begin{array}{c}\text { Membangun } \\
\text { Sistem Pelayanan } \\
\text { Kesehatan yang } \\
\text { Aman }\end{array}$} & \multicolumn{6}{|c|}{ Safe staffing } & \multirow{3}{*}{ OR } & \multirow{3}{*}{$\begin{array}{c}\text { Nilai } P \\
\text { value }\end{array}$} \\
\hline & \multicolumn{2}{|c|}{ Baik } & \multicolumn{2}{|c|}{ Tidak Baik } & \multicolumn{2}{|c|}{ Total } & & \\
\hline & $\mathrm{N}$ & $\%$ & $\mathrm{n}$ & $\%$ & $\mathrm{~N}$ & $\%$ & & \\
\hline Baik & 32 & 82,1 & 7 & 17,9 & 39 & 100 & \multirow{3}{*}{9,0} & \multirow{3}{*}{0,004} \\
\hline Tidak Baik & 0 & 0 & 9 & 100,0 & 9 & 100 & & \\
\hline Total & 32 & 66,7 & 16 & 33,3 & 48 & 100 & & \\
\hline
\end{tabular}

Berdasarkan analisis hubungan antara membangun sistem pelayanan kesehatan yang aman dengan Safe staffing diketahui bahwa dari 39 responden yang mempersepsikan membangun sistem pelayanan kesehatan yang aman dengan kategori baik sebanyak 32 responden atau 82,1\% mempersepsikan safe staffing sudah baik dan dari 9 responden yang mempersepsikan membangun sistem pelayanan kesehatan yang aman dengan kategori tidak baik tidak ada yang mempersepsikan safe staffing sudah baik

Hasil uji chi square didapatkan nilai $\mathrm{p}($ Value $)=0,004$ lebih kecil dari $\alpha=0,05$ sehingga dapat disimpulkan ada hubungan yang signifikan antara membangun sistem pelayanan kesehatan yang aman dengan Safe staffing dan dari hasil penelitian diperoleh nilai $\mathrm{OR}=9,0$ artinya membangun sistem pelayanan kesehatan yang aman mempunyai peluang 9,0 kali untuk menciptakan safe staffing dibandingkan dengan membangun sistem pelayanan kesehatan aman yang tidak baik.

\section{PEMBAHASAN}

\section{Hubungan ketersediaan sumber daya keperawatan dengan Safe staffing}

Berdasarkan analisis hubungan antara ketersediaan sumber daya keperawatan dengan safe staffing didapatkan 32 responden $(66,7 \%)$ jumlah total responden yang berpendapat safe staffing di RS Bhayangkaa sudah baik. 22 responden $(91,7 \%)$ menyatakan ketersediaan sumber daya keperawatan sudah baik. Hasil uji chi square didapatkan nilai p (value) $=0,001$ lebih kecil dari $\alpha=0,05$ sehingga dapat disimpulkan ada hubungan yang signifikan antara ketersediaan sumber daya keperawatan dengan Safe staffing dan dari hasil analisis diperoleh nilai OR = 15,4 artinya ketersediaan sumber daya keperawatan yang baik mempunyai peluang 15,4 kali untuk terciptanya safe staffing dibandingkan dengan ketersediaan sumber daya keperawatan yang tidak baik.

Menurut Cahyono (2008), kecukupan jumlah staf perawat yang sesuai dengan kompetensi, dan mampu bekerja sama dalam satu teamwork sehingga dapat memberikan keperawatan pasien yang aman sekaligus memberikan keamanan bagi perawat itu sendiri. Ketersediaan sumber daya keperawatan adalah tersedianya sumber daya manusia yang mendukung keselamatan, dan proses pelayanan yang dibangun sebagai sistem pertahanan terhadap risiko kesalahan. Salah satu aspek 
penting tercapainya mutu pelayanan di suatu rumah sakit adalah tersedianya tenaga keperawatan yang sesuai dengan situasi dan kebutuhan (Chayono, 2006).

Menurut Buchan, Parkin dan Sochalski (2003) mengusulkan sebuah kerangka tanggapan kebijakan terhadap kekurangan sumber daya keperawatan diantaranya yaitu: meningkatkan pasokan baru mulai dari pra-pendaftaran / pelatihan; meningkatkan retensi staf saat ini; meningkatkan pemanfaatan keterampilan perawat dan berkolaborasi dengan staf lain; mendorong kembalinya perawat yang saat ini tidak mengikuti pelatihan; dan mengatir udang-undang mengenai lingkup perekrutan tenaga perawat internasional yang etis.

Pelatihan merupakan salah satu bentuk upaya untuk meningkatkan pengetahuan dan keterampilan sumber daya manusia dalam rangka menjamin pelayanan yang aman dan bermutu. Institusi pelayanan kesehatan perlu menjamin tersedianya sumber daya manusia yang kompeten dan profesional (Cahyono, 2008)

Menurut Riza (2007), pada situasi terpuruknya tenaga keperawatan, seringkali perencanaan sumber daya keperawatan menjadi salah satu upaya penting untuk diperjuangkan. PPNI berperan penting untuk menyuarakan komunitas keperawatan, menegosiasikan suplai perawat yang memadai ketika memasuki dunia kerja dan mendorong kondisi kerja yang baik serta dapat membuat perawat yang kompeten betah bekerja dalam bidang kesehatan dan tidak meninggalkan profesi keperawatan.

Hasil penelitian menunjukkan fakta bahwa rumah sakit yang memiliki rasio perawat berbanding dengan pasien rawat inap 1: 8 mengalami lima kematian tambahan per 1.000 pasien dibandingkan rasio perawat-ke-pasien yang disesuaikan dengan standar BOR (Journal of American Medical Association, 2002).

Penelitian yang dilakukan Sheward, et.al, (2005) menunjukkan bahwa jumlah perawat berhubungan dengan kondisi kesehatan perawat. Perawat yang bekerja lembur terus menerus atau bekerja tanpa dukungan yang memadai cenderung untuk banyak tidak masuk kerja dan kondisi kesehatan yang buruk.

Berdasarkan penelitian (Baumann \& Blythe 2003) dalam California Nurses Association (CNA n.d.), rumah sakit dengan tingkat kepegawaian yang aman dapat mewujudkan penghematan finansial yang cukup besar.Staf yang tidak memadai menghasilkan biaya tambahan yang dikeluarkan melalui tingginya tingkat perputaran (turnover) perawat yang teregistrasi dan kebutuhan untuk mempekerjakan staf perawat sementara atau kontrak. Jangka panjang investasi pada staf yang cukup menghasilkan penghematan biaya. Perekrutan dan retensi staf yang aman telah berulang kali terbukti berkontribusi untuk hasil keperawatan pasien yang lebih baik, yang pada akhirnya terwujud dalam penurunan biaya kesehatan untuk individu, keluarga dan masyarakat dan kenaikan pendapatan pajak sebagai pasien yang kembali bekerja secara aktif.

Kalisch (2013), Jam Kerja Perawat Per Hari (HPPD) dan beban kerja yang dilaporkan perawat pada shift terakhir berkorelasi $(r=-276, p=0,008)$, dan persepsi tentang kecukupan beban kerja staf dan perawat yang dilaporkan pada shift terakhir berkorelasi $(\mathrm{r}=-384, \mathrm{P}=.000)$. Dalam analisis multivariabel, jumlah personil yang tidak memadai dikaitkan secara signifikan dengan kecukupan jumlah staf dan jumlah pasien yang dilaporkan perawat setiap unit secara signifikan terkait dengan Jam Kerja Perawat per Hari (HPPD) dan jumlah pasien yang dilaporkan perawat. Data ini menunjukkan bahwa tiga ukuran staf perawat tidak berkorelasi tinggi, dan dapat menangkap elemen yang berbeda dari konteks unit untuk menjelaskan staf perawat. Peneliti harus mempertimbangkan korelasi langkah-langkah ini saat memilih langkah-langkah perawat untuk mepersiapkan masa depan.

Berdasarkan hasil penelitian, teori yang ada dan berbagai penelitian yang terkait dengan ketersediaan sumber daya keperawatan dengan safe staffing, maka peneliti menyimpulkan bahwa untuk dapat terciptanya safe staffing bagi perawat, pihak administrator rumah sakit harus mampu memenuhi standar jumlah perawat yang tersedia. Ketersediaan jumlah sumber daya keperawatan tersebut tidak hanya berarti jumlah dan jenis tenaga keperawatan untuk memberikan asuhan keperawatan tetapi juga harus memperhatikan tingkat keahlian, pengalaman serta beban kerja yang 
dimilikinya sehingga tenaga keperawatan yang tersedia benar-benar kompeten dan mampu bekerja dengan baik tanpa adanya beban atau tekanan yang dapat menggangu kinerjanya.

\section{Hubungan Lingkungan kerja Perawat yang Kondusif dengan Safe staffing}

Hasil analisis hubungan antara lingkunan kerja perawat yang kondusif dengan Safe staffing didapatkan 32 responden $(66,7 \%)$ jumlah total responden yang berpendapat safe staffing di RS Bhayangkaa sudah baik. 24 responden $(80,0 \%)$ menyatakan kondisi lingkungan kerja yang kondusif di RS X sudah baik. Hasil uji chi square didapatkan nilai $\mathrm{p}(\mathrm{v}$ alue) $=0,027$ lebih kecil dari $\alpha=0,05$ sehingga dapat disimpulkan ada hubungan yang signifikan antara lingkungan kerja perawat yang kondusif dengan Safe staffing. dan dari hasil analisis diperoleh nilai $\mathrm{OR}=5,0$ artinya lingkungan kerja perawat yang baik mempunyai peluang 5,0 kali untuk terciptanya safe staffing dibandingkan dengan lingkungan kerja perawat yang tidak baik.

Menurut Barry Render \& Jay Heizer (2010), lingkungan kerja merupakan lingkungan fisik tempat karyawan bekerja yang mempengaruhi kinerja, keamanan dan mutu kehidupan kerja mereka. Lingkungan kerja yang kondusif memberikan rasa aman dan memungkinkan para pegawai untuk dapat bekerja optimal. Lingkungan kerja dapat mempengaruhi emosi pegawai, jika pegawai menyenangi lingkungan kerja dimana ia bekerja, maka pegawai tersebut akan betah di tempat bekerjanya untuk melakukan aktivitas sehingga waktu kerja dipergunakan secara efektif dan optimal prestasi kerja pegawai juga tinggi. Lingkungan kerja tersebut mencakup hubungan kerja yang terbentuk antara sesama pegawai dan hubungan kerja antar bawahan dan atasan serta lingkungan fisik tempat pegawai bekerja.

Lingkungan kerja yang positif bagi rumah sakit mampu mempengaruhi, mendorong dan memberikan motivasi bagi seseorang untuk bekerja secara optimal sesuai dengan profesinya sehingga tercapai kepuasan dalam bekerja. Pihak manajemen menyadari bahwa lingkungan yang tidak sehat mempengaruhi kesehatan fisik dan psikologis perawat seperti stres beban kerja yang berat, kerja berjam-jam, status profesional rendah, hubungan yang sulit dalam tempat kerja, masalah dalam menjalankan peran profesional, dan berbagai bahaya di tempat kerja (ICN, 2006).

Sebuah tempat kerja yang aman merupakan prasyarat untuk lingkungan praktek yang positif. Bahaya yang dialami perawat dan pasien merupakan dampak dari beban kerja yang berlebihan, dan kekerasan di tempat kerja. Beban kerja yang berlebihan timbul dari kurangnya kesesuaian antara tuntutan pekerjaan dengan kemampuan yang dimiliki perawat sehingga dapat mengancam kesehatan mereka dan menempatkan pasien pada risiko (ICN, 2007).

Penelitian menunjukkan bahwa perawat tertarik dan tetap berkerja di tempat mereka kerja ketika kesempatan yang ada memungkinkan untuk perawat maju dan profesional, serta mendapatkan otonomi dan dapat berpartisipasi dalam pengambilan keputusan, serta kompensasi yang cukup. Mempertahankan tingkat otonomi atas pekerjaan mereka memungkinkan perawat untuk merasa bahwa mereka dihormati dan dihargai anggota di tempat kerja mereka (ICN, 2007).

Matthew (2014) Perawatan di rumah sakit dengan lingkungan kerja yang baik dan buruk dikaitkan dengan kemungkinan penerimaan kembali yang $7 \%$ lebih rendah untuk gagal jantung (OR $=0,93,[0,89-0,97]) ; 6 \%$ lebih rendah untuk infark miokard $(\mathrm{OR}=0,94,[0,88-0,98])$; dan $10 \%$ lebih rendah untuk pasien pneumonia $(\mathrm{OR}=0,90,[0,85-0,96])$.

Ganey (2015) Penelitian menunjukkan bahwa lingkungan praktik keperawatan yang efektif sangat penting untuk memberikan perawatan bernilai tinggi di rangkaian perawatan akut rawat inap. Dalam laporan Press Ganey Special ini, analisis menunjukkan bahwa lingkungan kerja perawat dapat memiliki dampak yang jauh lebih besar dari kepegawaian yang aman.

Zurn, Dolea dan Stilwell (2005) melaporkan bahwa di Inggris, sebuah survei dari layanan kesehatan staf nasional di London menunjukkan bahwa, ketika saran bagi para pekerja kesehatan di minta untuk meningkatkan kerja mereka, 'gaji yang lebih baik' menduduki ranking empat di daftar keinginan mereka, dengan lebih banyak staf maka kondisi kerja yang lebih baik dan fasilitas yang lebih baik. Memang benar bagaimanapun, bahwa gaji lebih tinggi pada daftar kenginan staf, walaupun hanya peringkat kedua atau ketiga. Lingkungan kerja dari segi gaji dan insentif sangat mempengaruhi setiap pekerja agar dapat bekerja dengan aman dan nyaman. 
Dari hasil penelitian tersebut menunjukkan bahwa adanya Lingkungan kerja yang kondusif dapat memberikan jaminan kesehatan, keselamatan dan kesejahteraan pribadi dari staff, mendukung kualitas perawatan pasien dan meningkatkan motivasi, produktivitas dan kinerja individu dan organisasi. Lingkungan praktik positif bagi perawat (ICN, 2007).

Menurut ICN (2007) lingkungan yang tidak sehat dan kondusif mempengaruhi kesehatan fisik dan psikologis perawat melalui stres beban kerja yang berat, jam kerja yang panjang, status profesional rendah, hubungan sulit di tempat kerja, masalah melaksanakan peran profesional, dan berbagai bahaya di tempat kerja. Membangun lingkungan praktik positif di seluruh sektor kesehatan di seluruh dunia adalah sangat penting untuk terciptanya keselamatan pasien dan kesehatan petugas kesehatan. Semua pemangku kepentingan sektor kesehatan, baik itu atasan atau karyawan, swasta atau publik, pemerintah atau non-pemerintah, memiliki peran masing-masing dan spesifik. Peran dan tanggung jawab untuk menumbuhkan lingkungan kerja yang kondusif dan positif.

Menurut penelitian Awases et al., (2003) faktor utama yang menyebabkan ketidakpuasan kerja adalah kondisi kerja yang buruk, termasuk kekurangan peralatan, sarana dan prasarana. Pelatihan atau kualifikasi yang tidak memadai juga disebutkan sebagai masalah yang signifikan. Temuan ini didukung oleh sebuah survei yang dilakukan di lima negara Afrika, di mana motivasi rendah mengakibatkan migrasi Petugas kesehatan di luar negeri.

Berdasarkan hasil penelitian, teori yang mendukung serta penelitian yang terkait, maka peneliti berpendapat bahwa lingkungan kerja yang kondusif yang meliputi kondisi sarana prasarana, peralatan, fasilitas, kesejahteraan tenaga keperawatan memberikan kontribusi yang sangat tinggi terhadap keamanan dan keselamatan perawat itu sendiri. Sebab dengan semakin baiknya fasilitas dan sarana yang ada sangat membantu kinerja dari perawat itu sendiri, sementara adanya gaji dan tunjangan yang memadai akan menyebabkan perawat tetap bertahan di rumah sakit tersebut dan termotivasi untuk bekerja dengan baik tanpa adanya keinginan untuk bekerja di tempat yang lainnya, merasa sejahtera dan nyaman dalam bekerja.

\section{Hubungan Membangun Sistem Pelayanan Kesehatan yang Aman dengan Safe staffing}

Hasil analisis hubungan antara membangun sistem pelayanan kesehatan yang aman dengan Safe staffing didapatkan 32 responden $(66,7 \%)$ jumlah total responden yang berpendapat safe staffing di RS Bhayangkaa sudah baik. 32 responden $(82,1 \%)$ menyatakan membangun sistem pelayanan kesehatan yang aman di RS X sudah baik. Hasil uji chi square didapatkan nilai $\mathrm{p}($ Value $)=0,004$ lebih kecil dari $\alpha$ $=0,05$ sehingga dapat disimpulkan ada hubungan yang signifikan antara membangun sistem pelayanan kesehatan yang aman dengan Safe staffing.

Unsur keamanan yang ada dalam sistem pelayanan rumah sakit akan mengurangi insiden terjadinya penyakit dan cedera, memperpendek lama tindakan dan hospitalisasi, meningkatkan atau mempertahankan status fungsi klien dan meningkatkan kesejahteraan klien. Sistem pelayanan yang aman juga akan memberikan perlindungan kepada staffnya dan memungkinkan mereka dapat bekerja secara optimal. sistem yang aman adalah salah satu kebutuhan dasar yang terpenuhi (Potter \& Perry, 2009).

Menurut Cahyono (2008) membangun sistem pelayanan kesehatan yang aman bagi staf meliputi aspek bagaimana merancang sistem agar tidak terjadi kesalahan, bagaimana mendesain sistem agar setiap kesalahan dapat dilihat dan bagaimana merancang sistem agar efek suatu kesalahan dapat dikurangi.

WHO (2006) mengidentifikasi setidaknya enam dimensi mutu pelayanan kesehatan yang perlu diwujudkan oleh setiap negara, yaitu pelayanan kesehatan yang: efektif, efisien, mudah diakses, aman, tepat waktu dan mengutamakan pasien. Pemberian pelayanan menjadi prioritas utama bagi banyak negara; termasuk Indonesia, namun sulit untuk membuat pelayanan kesehatan terjangkau dan bermutu bagi masyarakat luas. Apabila suplai tenaga kesehatan dalam sistem kesehatan tidak memadai maka kualitas kehidupan kerja akan terpuruk.

Keberhasilan membangun safe staffing akan tercapai jika terdapat faktor-faktor pendukung yang saling berinteraksi. Faktor internal organisasi kesehatan dan eksternal berinteraksi satu sama lain. 
Faktor eksternal meliputi ketersediaan materi dan alat untuk meningkatkan keselamatan, kepemimpinan profesional yang kuat dan nyata, inisiasi legislatif dan regulasi yang ada, serta permintaan yang terus meningkat dari pelanggan terhadap keselamatan. Adapun faktor internal organiasai terdiri dari kepemimpinan, budaya organisasi untuk mengenali dan belajar dari kesalahan, serta program keselamatan pasien yang efektif. Dari keseluruhan faktor tersebut, motivasi intrinsik dari provider pelayanan kesehatan adalah yang paling menentukan (Cahyono, 2008).

Berdasarkan hasil penelitian dan teori-teori yang ada serta penelitian yang terkait peneliti berpendapat bahwa aspek sistem pelayanan kesehatan yang aman, meliputi rancangan sistem pencegahan terjadi kesalahan (error prevention), sistem yang dapat melihat dan memonitoring terjadinya kesalahan (making errors visible), dan sistem yang dapat mengurangi efek suatu kesalahan (mitigating the effects of errors) sangat penting dalam menciptakan safe staffing karena sistem tersebut dapat melakukan pencegahan secara preventif terhadap indikasi terjadinya kesalahan-kesalahan dalam pemberian asuhan keperawatan yang dapat berdampak terhadap keselamatan dan keamanan staff baik secara fisik maupun psikologis.

\section{KESIMPULAN}

Berdasarkan hasil penelitian tentang faktor-faktor yang mempengaruhi safe staffing di rumah sakit X Palembang tahun 2017, maka dapat diambil kesimpulan sebagai berikut: 1) Sebagian besar responden masih berusia muda dan produktif yaitu rata-rata berusia 27,19 tahun, jenis kelamin responden yang terbesar dalam penelitian ini yaitu perempuan sebanyak 34 responden $(70,8 \%)$, tingkat pendidikan responden yang terbanyak dalam penelitian ini yaitu D.III Keperawatan sebanyak 38 responden $(79,2 \%)$, rata-rata lama masa kerja responden pada penelitian ini yaitu 4,25 tahun. 2) Ketersediaan sumber daya keperawatan sudah baik sebanyak 24 responden atau 50\%, lingkungan kerja yang kondusif sudah baik sebanyak 30 responden atau $62,5 \%$, membangun sistem pelayanan kesehatan yang aman sudah baik sebanyak 35 responden atau 72,9\%, dan Safe staffing sudah baik sebanyak 32 responden atau 66,7\%.). 3) Ada hubungan yang signifikan antara ketersediaan sumber daya keperawatan dengan Safe staffing $\mathrm{p}($ value $)=0,001$. 4) Ada hubungan yang signifikan antara lingkungan kerja perawat yang kondusif dengan Safe staffing $\mathrm{p}(\mathrm{value})=0,027$. 5) Ada hubungan yang signifikan antara membangun sistem pelayanan kesehatan yang aman dengan Safe staffing $\mathrm{p}($ Value $)=$ 0,004 .

Berdasarkan hasil penelitian dan kesimpulan yang ada, penulis menyarankan: 1) Bidang keperawatan bersama-sama dengan Komite Keselamatan Rumah Sakit dapat mengembangkan perencanaan peningkatan kualitas SDM melalui pelatihan dan pendidikan sesuai kompetensi perawat, memberikan reward kepada perawat, peningkatan status perawat secara berkesinambungan sesuai kinerjanya sehingga dapat tercipta lingkungan kerja yang kondusif dan perawat dapat memberikan pelayanan kesehatan yang aman. 2) Agar mengoptimalkan fungsi K3RS sebagai jembatan atau media bagi perawat agar dapat terjamin keamanan dan keselamatannya melalui perlindungan yang diberikan oleh komite ini, sebab persyaratan untuk akreditas sebuah rumah sakit harus memiliki komite yang independen yang mampu memberikan kepastian hukum terhadap pasien dan perawat. 3) Agar meningkatkan sarana dan prasarana yang mendukung terciptanya lingkungan kerja yang kondusif bagi perawat maupun pasien. 4) Mengembangkan penelitian mengenai faktor-faktor yang berhubungan dengan safe staffing dengan mempertimbangkan tingkat pendidikan usia dan lama kerja responden pada kelompok responden yang dilibatkan. 5) Mengembangkan penelitian yang tidak terbatas hanya pada faktor-faktor yang berhubungan dengan safe staffing, tetapi juga penelitian yang dikembangkan untuk mengukur efektifitas komite keselamatan dan kesehatan kerja di rumah sakit dengan terciptanya safe staffing. 6) Mengembangkan penelitian dengan desain penelitian yang berbeda dengan tujuan menggali berbagai fenomena mengenai persepsi, pengalaman dan kontribusi perawat terkait berbagai topik keselamatan staff dalam pelayanan keperawatan. 7) Menjadikan keselamatan perawat (safe staffing) sebagai bahan kajian yang harus dikembangkan dalam kurikulum pendidikan tinggi keperawatan untuk penguasaan kompetensi dasar keselamatan sebagai bekal bagi mahasiswa pada saat terjun ke dunia 
kerja. 8) Diharapkan berpartisipasi dalam pengembangan safe staffing melalui kerjasama dengan institusi pelayanan dalam bentuk pelatihan yang mengacu pada modul yang telah dibuat, penelitian, dan penyusunan standar kinerja keselamatan perawat

\section{DAFTAR PUSTAKA}

American Nurses Association, (2016). Safe staffing. http://www.rnaction.org/site/PageNavigator/nstat_take_action_safe_staffing.html. diakses tanggal 15 Januari 2017

Awases et al., (2003). Migrasi tenaga kesehatan di enam negara: Laporan sintesis, Organisasi Kesehatan Dunia, Kantor Regional untuk Afrika, Brazzaville.(online). http://curationis.org.za/

Barry Render \& Jay Heizer (2010), http://elib.unikom.ac.id/files/disk1/571/jbptunikompp-gdlnitalestar-28532-10-unikom_n-i.pdf

Baumann \& Blythe, (2003), Internationally educated health professionals: workforce integration and retention. (online). https://www.ncbi.nlm.nih.gov/pubmed/20523135

Buchan, J., Parkin, T., \& Sochalski, J. (2003). International nurse mobility trends and policy implications. Publications of the World Health Organization, Geneva Switzerland (online) http://www.nursingworld.org/MainMenuCategories/ANAMarketplace/ANAPeriodicals/OJI N/TableofContents/vol132008/No2May08/LatinAmericanPerspective.aspx

Cahyono, J.B Suharjo. (2008). Membangun Budaya Keselamatan Pasien dalam Praktik kedokteran. Yogyakarta: Kanisius.

Fera, Retno Magentang. (2015). Pentingnya Pengembangan Kompetensi SDM di Rumah Sakit (Article). 25 Juni 2014. http://www.kompasiana.com /feraretno/pentingnya-pengembangan-kompetensisdm-di-rumah-sakit_54f6e140a33311df5b8b4a08. Diakses tanggal 20 Desember 2016

Ganey. (2015). Nursing Special Report: The Influence of Nurse Work Environment on Patient, Payment and Nurse Outcomes in Acute Care Settings. Retrieved from: http://healthcare.pressganey.com/2015Nursing-SR_Influence_Work_Environment

Hafizurrachman HM , dkk,2011, Beberapa Faktor yang memengaruhi Kinerja Perawat dalam Menjalankan Kebijakan Keperawatan di Rumah Sakit Umum Daerah J Indon Med Assoc,Volum: 61, Nomor: 10, Oktober 2011

International Council of Nurse \& World Health Organization. (2007). Islamabad declaration on strengthening nursing and midwifery. Juni 23, 2008.http://www.icn.ch. diakses tanggal 12 Januari 2017

International Council of Nurse. (2006). International nursing day, safe staffing and saves lives: information and action tool kit. Geneva: The Author. Juni 23, 2008.http://www.icn.ch. Diakses tanggal 20 Desember 2016

International Council of Nurse. (2007). International nursing day, positive practice environment:quality workplaces = quality patient care. Information and action tool kit. Geneva: The Author. Desember 25, 2009. http://www.icn.ch. Diakses tanggal 20 Desember 2016

Iskandar (2008). Manajemen Sumber Daya Manusia Dilengkapi dengan Perilaku Organisasi Teori dan Penerapan. Bandung: Multazam

Journal of American Medical Association, (2002 ).Safe Staffing Saves Lives (online), http://www.nysna.org/sites/default/files/attach/398/2013/12/SafeStaffingFactsheet.pdf)

Kalisch, B.J., Labelle, A.E., \& Boqin, X. (2013). Nursing teamwork and time to respond to call lights: an exploratory study. Revista Latino-Americana de Enfermagem, 21(Spec), 242-9. Retrieved from: http://www.scielo.br/scielo.php?script=sci_arttext\&pid=S0104$11692013000700030 \& \operatorname{lng}=$ en\&nrm=iso\&tlng=en

McHugh, M., \& Ma, C. (2013). Hospital nursing and 30-day readmissions among Medicare patients with health failure, acute myocardial infarction, and pneumonia. Medical Care, 51(1), 52-59. Retrieved from: https://www.ncbi.nlm.nih.gov/pmc/articles/PMC3593602/ 
Neila (2013), Karir Perawat Pengaruhi Mutu Pelayanan Keperawatan. (online) https://www.ugm.ac.id/id/berita/8489-karir.perawat.pengaruhi.mutu. pelayanan.keperawatan.

Nursalam. (2010). Konsep Dan Penerapan Metodologi Penelitian Ilmu Keperawatan. Edisi 2. Jakarta : Salemba Medika

Nursalam. (2013). Metodologi Penelitian Ilmu Keperawatan: Pendekatan Praktis. Ediisi 3. Jakarta: Salemba Medika

Riza (2007,) safe-staffing-dalam-pelayanan-kesehatan. bppsdmk.depkes.go.id, diakses tanggal 20 April 2017

Robbins SP, dan Judge. (2008). Perilaku Organisasi Buku 2, Jakarta : Salemba. Empat

Saksono, Slamet. (2014). Administrasi Kepegawaian. Yogyakarta: Kanisius

WHO (2006), Laporan Kesehatan Dunia 2006 - Bekerja Sama untuk Kesehatan (online) http://www.who.int/whr/2006/ Diakses tanggal 24 Desember 2016

Zurn, P., Dolea, C., \& Stilwell, B. (2005) Nurse retention and recruitment: Developing a motivated workforce. The Global Nursing Review Initiative (pp. 17 - 23). International Council of Nurses, Geneva, Switzerland.(online) http://www.nursingworld.org 